\title{
Fault Location Effect on Short-Circuit Calculations of a TCVR Compensated Line in Algeria
}

\author{
Mohamed Zellagui*, Heba Ahmed Hassan**, Abdelaziz Chaghi* \\ * LSTE Laboratory, Department of Electrical Engineering, Faculty of Technology, University of Batna, Algeria \\ ** Department of Electrical and Computer Engineering, College of Engineering, Dhofar University, Sultanate of Oman \\ \& Electrical Power and Machines Department, Faculty of Engineering, Cairo University, Egypt
}

\begin{tabular}{l} 
Article Info \\
\hline Article history: \\
Received Sep 8, 2014 \\
Revised Dec 2, 2014 \\
Accepted Dec 26, 2014 \\
\hline
\end{tabular}

\section{Keyword:}

Fault Location

Phase to Earth Fault

Power Systems

Short-Circuit Calculations

TCVR FACTS Device

\begin{abstract}
This research work investigated the effect of fault location on short-circuit calculations for a high voltage transmission line equipped with a novel FACTS device, namely Thyristor Controlled Voltage Regulator (TCVR). This main function of this device was to control the voltage and active power of the line. The paper considered a study case for a $220 \mathrm{kV}$ transmission line, in the Algerian transmission power network, which was subjected to a phase to earth fault in the presence of a fixed fault resistance. The paper presented theoretical analysis of the short-circuit calculations which was confirmed by the illustrated simulation results. Simulation results showed the impact of the fault location on the symmetrical current and voltage components of the line, and transmission line phase currents and voltages; before using TCVR and in the presence of TCVR for both cases of positive and negative TCVR controlled voltage.
\end{abstract}

Copyright (C) 2015 Institute of Advanced Engineering and Science. All rights reserved.

\section{Corresponding Author:}

Dr. Mohamed Zellagui,

Department of Electrical Engineering, Faculty of Technology, University of Batna,

Campus CUB, Street Med El Hadi Boukhlouf, 05000, Batna, Algeria.

Email: m.zellagui@univ-batna.dz

\section{INTRODUCTION}

Short-circuit calculations in power systems are important. These calculations enable power engineers to determine the ratings of electrical equipment which can withstand thermal and electromagnetic effects of the short-circuit current. They significantly help to determine the settings and coordination of the protection equipment in the system according to well established national and international standards such as IEC and ANSI/IEEE [1].

The selection of a circuit breaker for a power system depends, not only upon the current tie breaker is to carry under normal operating conditions, but also upon the maximum current it may have to carry momentarily and the current it may have to interrupt at the voltage of the line in which it is placed. The current which a breaker must interrupt is usually asymmetrical since it still contains some of the decaying DC components [2]. This current is properly called the rated symmetrical short-circuit current or the required symmetrical interrupting capability. It is necessary to determine the likely fault currents in a system under various fault conditions before selecting proper protection devices. Depending upon the complexity of the system, the calculations could also be too much involved.

Accurate fault current calculations are normally carried out using symmetrical components as an analytical technique used by design engineers and practicing protection engineers [3]. It is based on the principle that any unbalanced set of vectors can be represented by a set of three balanced quantities, namely direct, inverse and zero sequence.

In literature, many researchers have focused on the impact of fault conditions on power systems such as the error in estimated fault distance in case of ground faults [4], fault location in distribution system 
[5], fault location for transmission system using sparse measurement method [6], fault location for hybrid transmission lines [7], distance protection performance [8], adaptive digital distance relaying scheme for double transmission line [9], adaptive digital relaying scheme to tackle fuse re-closure and lack of coordination in case of Distributed Generation (DG) [10], adaptive reach settings of distance relay on a transmission line in presence of UPFC [11], and bus-bar protection [12].

In [13], a study of the impact of DG on overcurrent protection has been investigated using a typical UK rural distribution network while considering relevant factors for fault current including arc fault. A fault location approach has been proposed for the distribution network incorporating DGs [14].

The impact of fault resistance on the measured impedance by distance relay in the presence TCSC has been investigated [15], the impact of fault resistance on zero-sequence current and fault component reactance relays has been studied [16], and the effect of fault condition on performance of distance relay protection in the presence series FACTS device on transmission line has been addressed [17].

In the light of the rapid development of Flexible AC Transmission Systems (FACTS) devices as well as their numerous advantages in power systems control, fault calculations should be considered to include the presence of these devices in the system. In a meshed power network and under steady state conditions, FACTS devices allow transmission lines to operate close to their thermal limits and to reduce the loop flows by providing or absorbing reactive power, increasing or reducing voltage and control series impedance or phase-angle.

One of the recent FACTS devices is the Thyristor Controlled Voltage Regulator (TCVR) which is deployed in this research work. Therefore, this research work contributes to the investigation of the phase to earth fault calculations while using TCVR device which aims to control the voltage and active power of the line through a TCVR controller voltage, denoted by $V_{T C V R}$. This paper analyses the effect of the fault location, for either $10 \mathrm{kV}$ increment or $-10 \mathrm{kV}$ decrement of $V_{T C V R}$ voltage, on the symmetrical current and voltage components as well as the line phase currents and voltages, in case of a phase $A$ to earth fault for a transmission line compensated by TCVR in $220 \mathrm{kV}$ Algerian network. TCVR device is located at the mid of the line, between Batna and Biskra $220 / 60 \mathrm{kV}$ substations in the presence of a fixed fault resistance. The paper presents the theoretical analysis which is derived and verified by simulation results in the absence and presence of TCVR.

\section{TCVR CONTROLLED VOLTAGE}

The rapid speed of FACTS devices offers several benefits to system operation and control in dynamic stability studies. In addition, FACTS devices have benefits in case of short-circuits by limiting the short-circuit current [18]. Another advantage of FACTS devices is giving the opportunity to extend the current transmission line limits in a step-by-step manner with an incremental investment when required. Furthermore, FACTS controllers offer the possibility to move an installation when it becomes not useful anymore. Different types of devices have been developed and there are various ways to classify them in terms of the technology of the used semiconductor, the possible benefits of the controllers, and the type of compensation and connection.

Figure 1 shows the active power flow equation between two buses 1 and 2 and the variables that can be modified by each FACTS device [19].

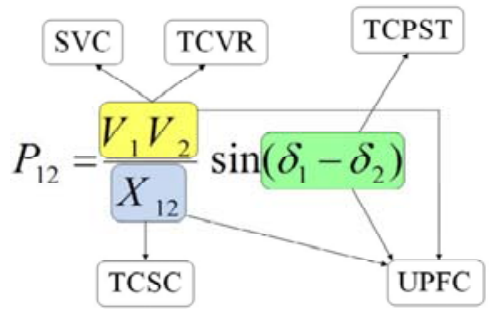

Figure 1. Effects of FACTS devices on active power equation

$V_{1}$ and $V_{2}$ are the voltage magnitudes of buses 1 and 2, $X_{12}$ is the transmission line reactance and $\left(\delta_{1}-\delta_{2}=\delta\right)$ is the difference in phase angle between the two phasor voltages of $V_{1}$ and $V_{2}$.

The FACTS device employed in this paper is the TCVR which operates by inserting an in-phase voltage to the main bus voltage to change its magnitude. To model TCVR, an ideal tap changer transformer 
can be used without series impedance as in Figure 2. The value of the turn's ratio is given by the ratio of the additional transformation relative to the nominal transformation and its values range between 0.9 and 1.1 ; where unity value corresponds to no additional transformation [18].

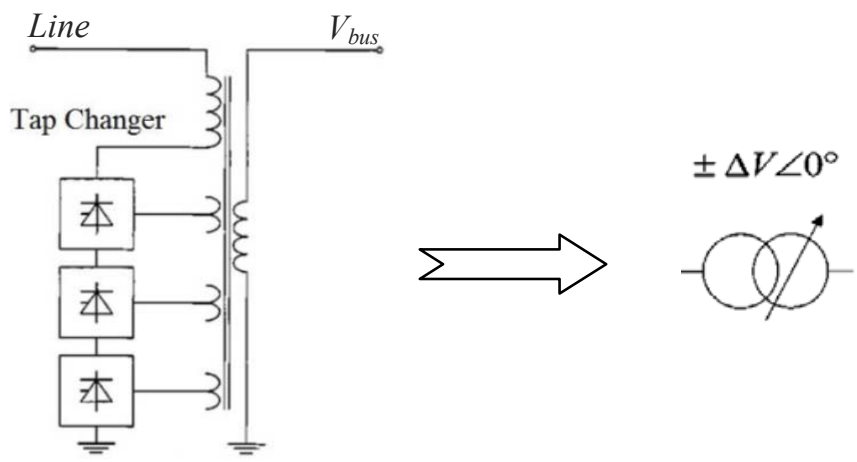

Figure 2. Model of TCVR

Therefore, TCVR can be modeled as an ideal tap changer transformer without series impedance [18], [19]. The TCVR coefficient $K_{T C V R}$ takes the following ranges, as presented by the following equations:

$$
\begin{aligned}
& V_{T C V R}=K_{T C V R} \cdot V_{b u s} \\
& -0.15 \leq K_{T C V R} \leq+0.15 \\
& -0.15 \times V_{b u s} \leq V_{T C V R} \leq+0.15 \times V_{\text {bus }}
\end{aligned}
$$

\section{PHASE TO EARTH FAULT CALCULATIONS IN PRESENCE OF TCVR}

Symmetrical components method has always been used in the analysis of unbalanced three-phase systems, unsymmetrical fault currents, and rotating electrodynamics machinery. It was originally presented by C. L. Fortescue in 1918 and has been popular ever since [20], [21]. The basic theory of symmetrical components can be stated as a mathematical concept. A system of three coplanar vectors is completely defined by six parameters, and the system can be said to possess six degrees of freedom. A point in a straight line, being constrained to lie on the line, possesses one degree of freedom, and by the same analogy, a point in space has three degrees of freedom. A coplanar vector is defined by its terminal and length; therefore it possesses two degrees of freedom. Figure 3 shows the equivalent circuit of a transmission line model, compensated by TCVR and subjected to a phase A to earth fault, in the presence of fault resistance $\left(R_{F}\right)$.

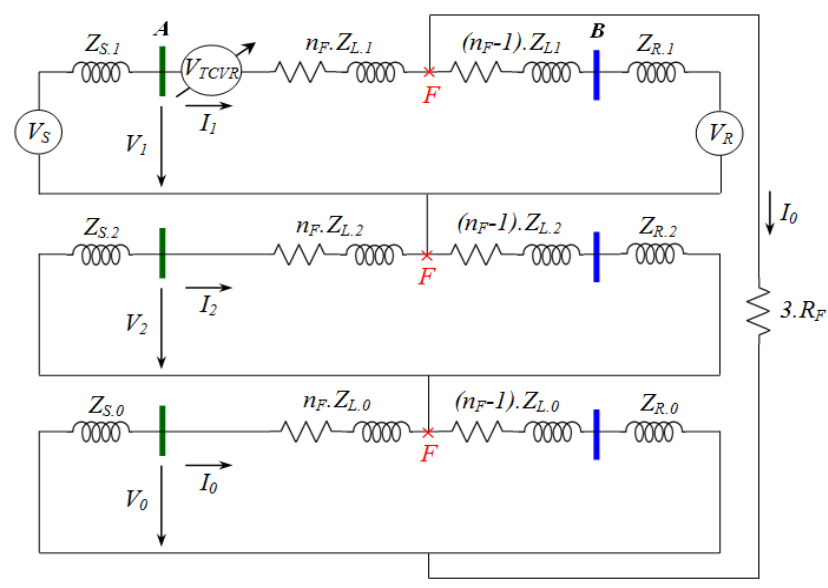

Figure 3. Equivalent circuit model of a phase to earth fault while using TCVR [22] 
The basic equations for this type of fault take the following form [1], [23]:

$$
\begin{aligned}
& I_{B}=I_{C}=0 \\
& V_{A}=V_{1}+V_{2}+V_{0}=R_{F} \times I_{A} \neq 0
\end{aligned}
$$

The symmetrical components of the currents are [23], [24]:

$$
\left[\begin{array}{l}
I_{0} \\
I_{1} \\
I_{2}
\end{array}\right]=\frac{1}{3}\left[\begin{array}{ccc}
1 & 1 & 1 \\
1 & a & a^{2} \\
1 & a^{2} & a
\end{array}\right] \times\left[\begin{array}{c}
I_{A} \\
I_{B} \\
I_{C}
\end{array}\right]
$$

From equation (4) and matrix (6), the symmetrical components of the currents take the following form:

$$
I_{1}=I_{2}=I_{0}=\frac{I_{A}}{3}
$$

The symmetrical components of the voltages are:

$$
\left[\begin{array}{l}
V_{0} \\
V_{1} \\
V_{2}
\end{array}\right]=\frac{1}{3}\left[\begin{array}{ccc}
1 & 1 & 1 \\
1 & a & a^{2} \\
1 & a^{2} & a
\end{array}\right] \times\left[\begin{array}{c}
V_{A} \\
V_{B} \\
V_{C}
\end{array}\right]
$$

From equations (5) and (8), the direct component of the voltages becomes:

$$
\begin{aligned}
& V_{1}=-\left(V_{0}+V_{2}\right)+\left(R_{F} \times I_{A}\right) \\
& V_{S} \pm V_{T C V R}-M_{1}=-\frac{1}{3}\left[-M_{0}\right]-\frac{1}{3}\left[-M_{2}\right]+R_{F} \times I_{A}
\end{aligned}
$$

where,

$$
\begin{aligned}
& M_{1}=\left(n_{F} \cdot Z_{L 1}\right) \times I_{1} \\
& M_{0}=\left(n_{F} \cdot Z_{L 0}\right) \times I_{0} \\
& M_{2}=\left(n_{F} \cdot Z_{L 2}\right) \times I_{2} \\
& V_{S} \pm V_{T C V R}=\frac{I_{A}}{3}\left[n_{F} \cdot\left(Z_{L 1}+Z_{L 2}+Z_{L 0}\right)\right]+R_{F} \times I_{A}
\end{aligned}
$$

From equations (12), the fault current of phase A in the presence of a TCVR is given by:

$$
I_{A}=\frac{3 \times\left(V_{S} \pm V_{T C V R}\right)}{n_{F} \times\left(Z_{L 1}+Z_{L 2}+Z_{L 0}\right)+\left(3 \times R_{F}\right)}
$$

From equations (7) and (13), the current symmetrical components in the presence of TCVR are given by:

$$
I_{1}=I_{2}=I_{0}=\frac{\left(V_{S} \pm V_{T C V R}\right)}{n_{F} \times\left(Z_{L 1}+Z_{L 2}+Z_{L 0}\right)+\left(3 \times R_{F}\right)}
$$

The direct symmetrical component of the voltages is defined by:

$$
\begin{aligned}
& V_{1}=V_{S} \pm V_{T C V R}-M_{1} \\
& V_{1}=\frac{\left(V_{S} \pm V_{T C V R}\right) \times\left[Z_{L 2}+Z_{L 0}-\left(2 \times Z_{L 1}\right)+\left(3 \times R_{F}\right)\right]}{n_{F} \times\left(Z_{L 1}+Z_{L 2}+Z_{L 0}\right)+\left(3 \times R_{F}\right)}
\end{aligned}
$$


The inverse symmetrical component of the voltages is defined by:

$$
\begin{aligned}
& V_{2}=-M_{2} \\
& V_{2}=-\frac{\left(V_{S} \pm V_{T C V R}\right) \times Z_{L 2}}{n_{F} \times\left(Z_{L 1}+Z_{L 2}+Z_{L 0}\right)+\left(3 \times R_{F}\right)}
\end{aligned}
$$

The zero symmetrical component of the voltages is given by:

$$
\begin{aligned}
& V_{0}=-M_{0}-\left(R_{F} \times I_{0}\right) \\
& V_{0}=-\frac{\left(V_{S} \pm V_{T C V R}\right) \times\left(Z_{L 0}+R_{F}\right)}{n_{F} \times\left(Z_{L 1}+Z_{L 2}+Z_{L 0}\right)+\left(3 \times R_{F}\right)}
\end{aligned}
$$

The coefficients $A_{a}$ to $A_{f}$ are defined as follows:

$$
\begin{aligned}
& A_{a}=a^{2}-a \\
& A_{b}=a^{2}-1 \\
& A_{c}=3 \times a^{2}-1 \\
& A_{d}=a-a^{2} \\
& A_{e}=a-1 \\
& A_{f}=3 \times a-1
\end{aligned}
$$

From equations (16), (18), (20) and matrix (8), the three phase voltages of the transmission line in the presence of TCVR take the following form:

$$
\begin{aligned}
& V_{A}=\frac{3 \times R_{F} \times\left(V_{S} \pm V_{T C V R}\right)}{n_{F} \times\left(Z_{L 1}+Z_{L 2}+Z_{L 0}\right)+\left(3 \times R_{F}\right)} \\
& V_{B}=\frac{\left.\left(V_{S} \pm V_{T C V R}\right) \cdot\left[A_{a} \times Z_{L 2}+A_{b} \times Z_{L 0}+A_{c} \times R_{F}\right)\right]}{n_{F} \times\left(Z_{L 1}+Z_{L 2}+Z_{L 0}\right)+\left(3 \times R_{F}\right)} \\
& V_{C}=\frac{\left.\left(V_{S} \pm V_{T C V R}\right) \times\left[A_{d} \times Z_{L 2}+A_{e} \times Z_{L 0}+A_{f} \times R_{F}\right)\right]}{n_{F} \times\left(Z_{L 1}+Z_{L 2}+Z_{L 0}\right)+\left(3 \times R_{F}\right)}
\end{aligned}
$$

From what is above, it is clear that the short-circuit calculations depend on the following: TCVR controlled voltage $\left(V_{T C V R}\right)$ and operation mode, and the fault conditions represented in fault location $\left(n_{F}\right)$ and fault resistance $\left(R_{F}\right)$. While using a fixed fault resistance, the effect of fault location is studied, in the absence of TCVR and in its presence for positive and negative TCVR controlled voltage, as shown in the next section.

\section{RESULTS AND ANALYSIS}

The electrical network studied in this paper is for the Eastern Algerian transmission network, Sonelgaz group which is the National Society for Electricity and Gas in Algeria, as shown in Figure 4 [25]. It is a state-owned utility in charge of electricity and natural gas transmission and distribution in Algeria, established in 1969.

The case study of this research work is for a $220 \mathrm{kV}$ transmission line which connects Batna and Biskra 220/60 kV substations in the mentioned network. The line is equipped with a TCVR device installed at its midpoint. The voltage controlled by the installed TCVR system $\left(V_{T C V R}\right)$ varies between minimum of 
$-10 \mathrm{kV}$, and a maximum of $+10 \mathrm{kV}$. The fault location $n_{F}$ varies between $50 \%$ (at the mid of the line) to 100 $\%$ (at the end of the line at bus-bar $B$ ). A fault resistance $R_{F}$ is used whose magnitude is maintained at $20 \Omega$.

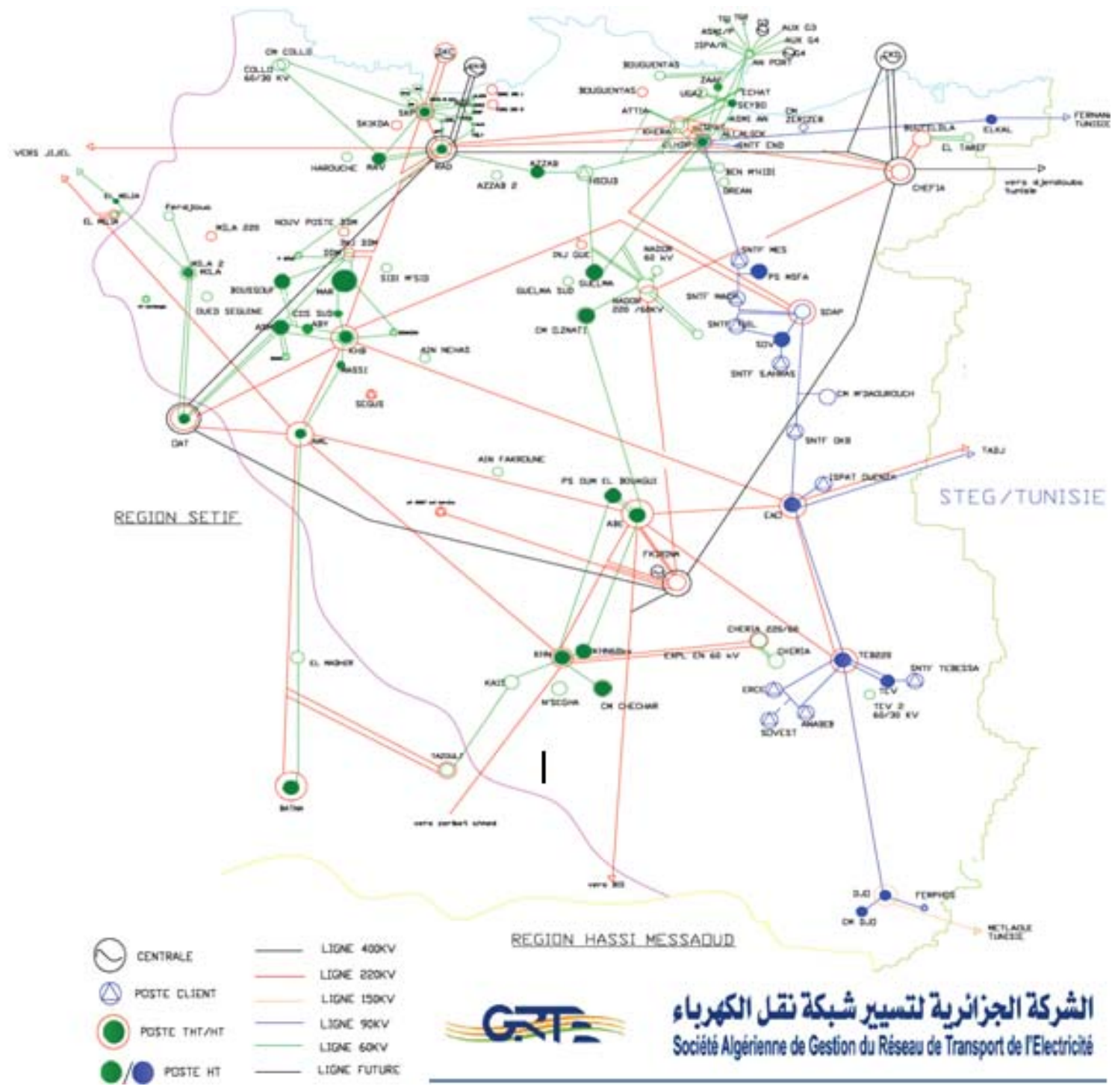

Figure 4. Eastern region of Algerian transmission network

Figures 5.a, b, c represent the variation of the current symmetrical components $\left(I_{1}, I_{2}\right.$ and $\left.I_{0}\right)$, respectively and Figures $6 . \mathrm{a}, \mathrm{b}$, c represent the variation of the line currents $\left(I_{A}, I_{B}\right.$ and $\left.I_{C}\right)$, respectively as a function of the fault location $n_{F}$ without and with TCVR. As earlier mentioned while using TCVR, cases are studied for $V_{T C V R}$ decrement and increment such that $V_{T C V R}$ is either equal to $-10 \mathrm{kV}$ or $+10 \mathrm{kV}$, respectively.

Figures 5.a, b, c, also shows that the three symmetrical current components are equal, in each individual case of using TCVR and without it, which matches equation (7). It is also clear that increasing the value of $n_{F}$ leads to a decrement in the magnitude of the current symmetrical components, in the absence and presence of TCVR. This is expected due to increasing the short-circuit impedance as a result of adding more line impedance when $n_{F}$ increases. 


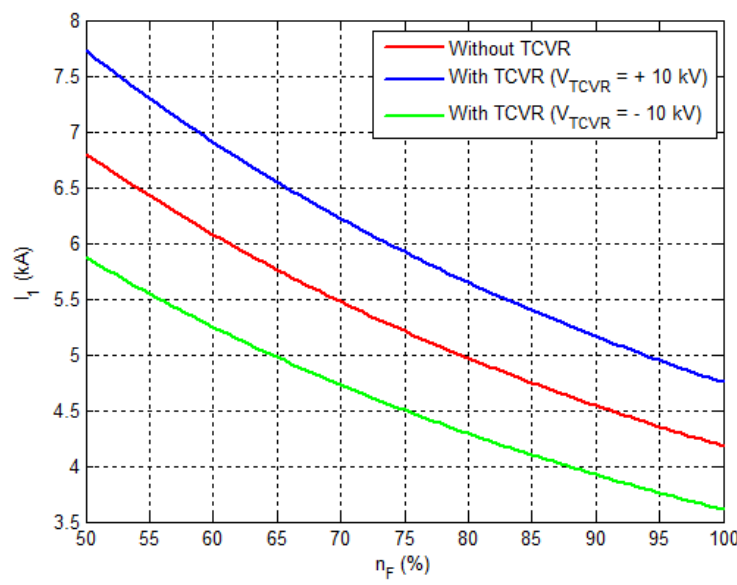

(a)

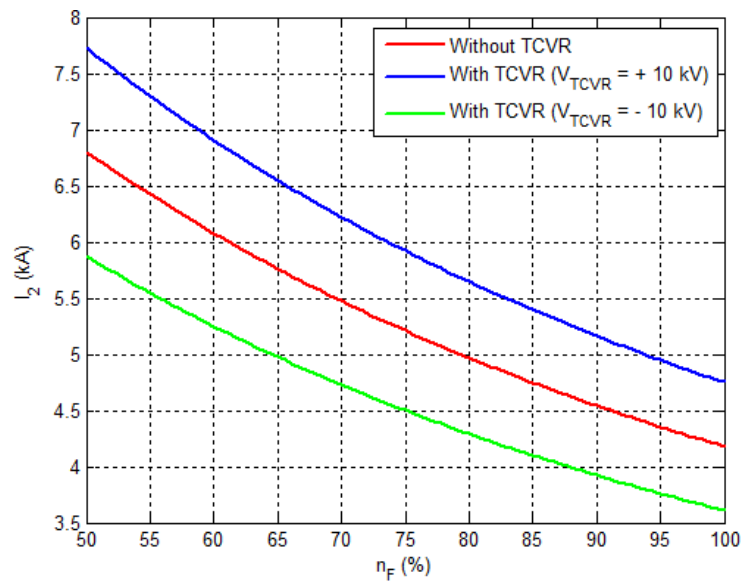

(b)

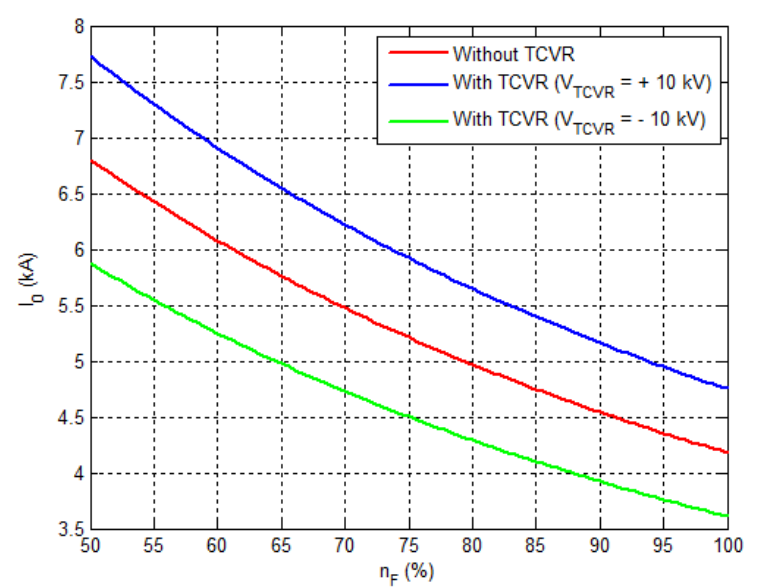

(c)

Figure 5. Impact of $n_{F}$ on the current symmetrical components

In Figures 6.a, b, c, it is noticeable that the line currents of phases $B$ and $C$ are always zero which is confirmed by equation (4). However, increasing the value of $n_{F}$ shows a reduction in the line current of the faulty phase $A$ in all studied cases; before and after using TCVR. This is also attributed to the increase of the short-circuit impedance with the increase of $n_{F}$.

Figures 7.a, b, c represent the variation of the voltage symmetrical components $\left(V_{l}, V_{2}\right.$ and $\left.V_{0}\right)$ respectively and Figures $8 . \mathrm{a}, \mathrm{b}, \mathrm{c}$ represent the variation of the line phase voltages $\left(V_{A}, V_{B}\right.$ and $\left.V_{C}\right)$, respectively as a function of the fault location $n_{F}$ without and with TCVR, where $V_{T C V R}$ is $-10 \mathrm{kV}$ or $+10 \mathrm{kV}$.

In Figures 7.a, b, c, the increase of $n_{F}$ value leads to a decrease in the direct voltage component, while the inverse and zero voltage components are shown to increase. This is valid for each individual case, whether TCVR is installed or not, which is confirmed by equations (16), (18) and (20).

In Figures 8.a, b, c, it is observed that the increase of $n_{F}$ value leads to a decrease in the value of phase $A$ and $B$ voltages, while the voltage of phase $C$ shows an increment with the increase of $n_{F}$ for all cases.

In the above studied cases when using TCVR, it is observed that the graphs corresponding to $V_{T C V R}$ equals to $+10 \mathrm{kV}$ show higher magnitudes than those corresponding to $V_{T C V R}$ of $-10 \mathrm{kV}$ which is normally expected. 


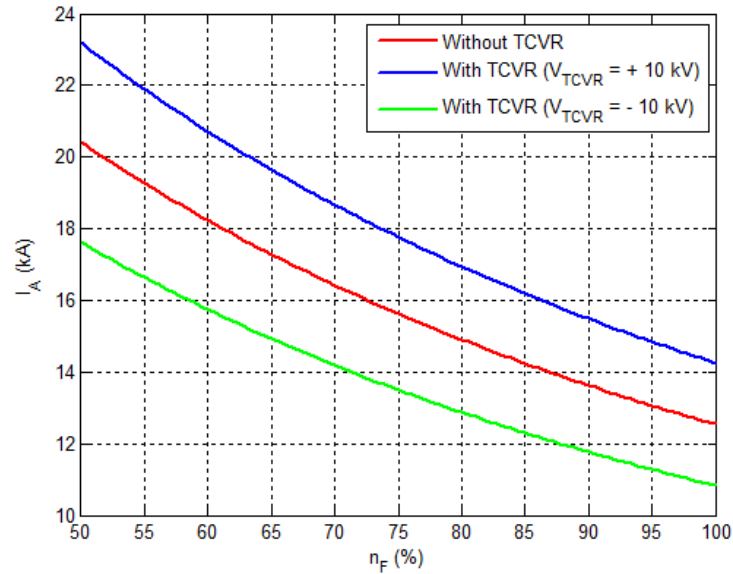

(a)

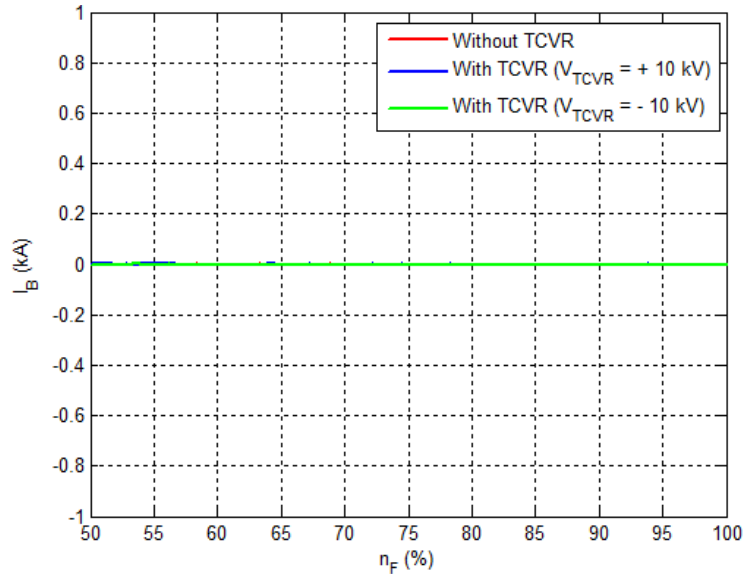

(b)

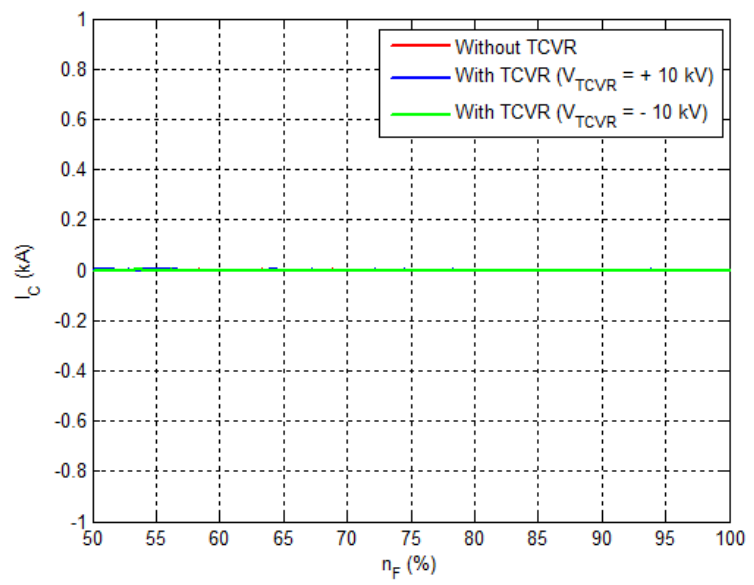

(c)

Figure 6. Impact of $n_{F}$ on the transmission line currents 


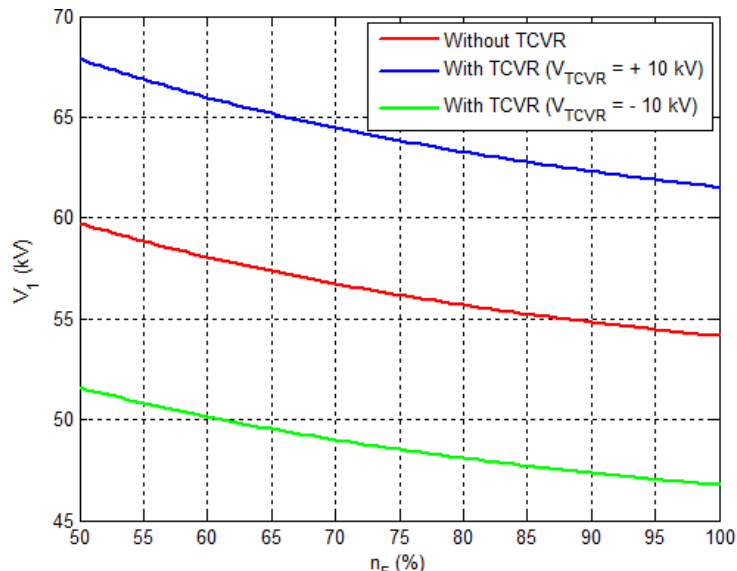

(a)

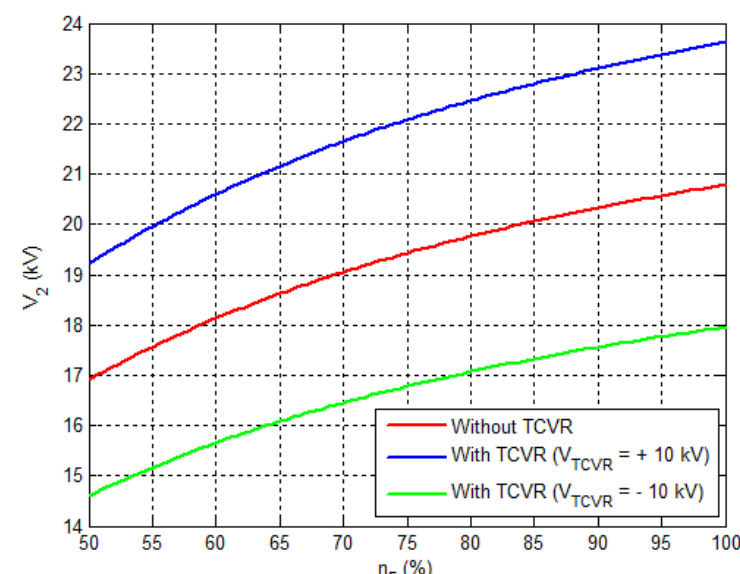

(b)

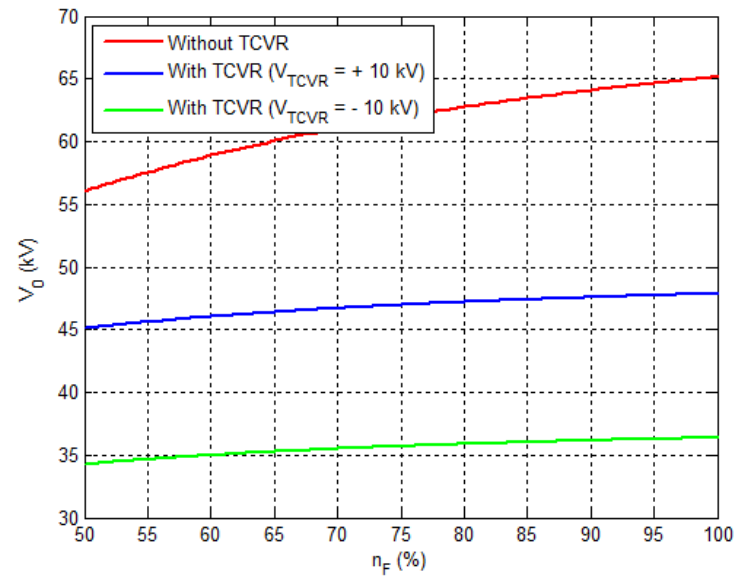

(c)

Figure 7. Impact of $n_{F}$ on the voltage symmetrical components 


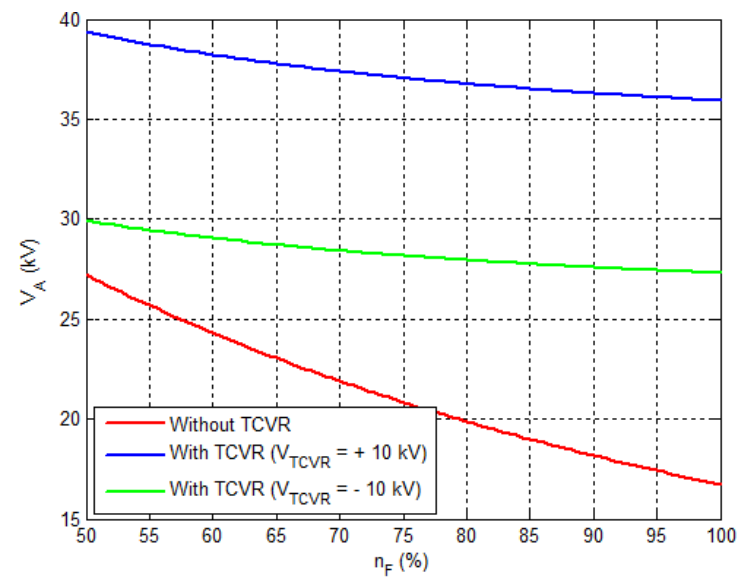

(a)

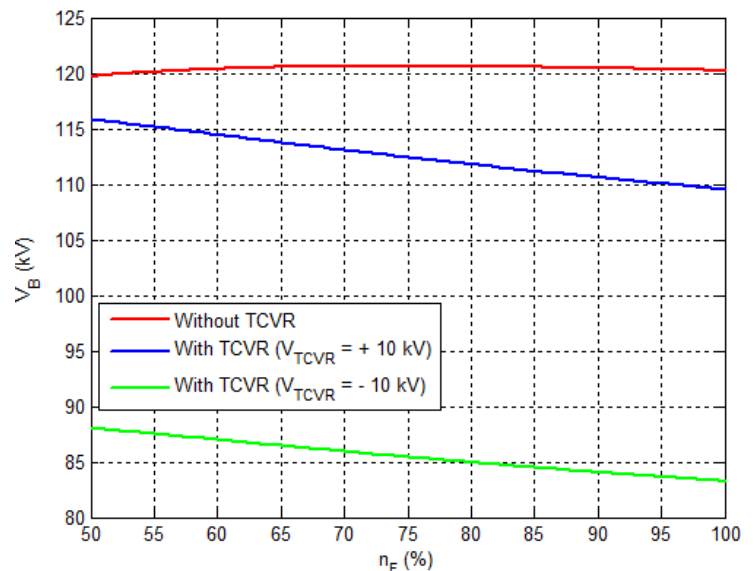

(b)

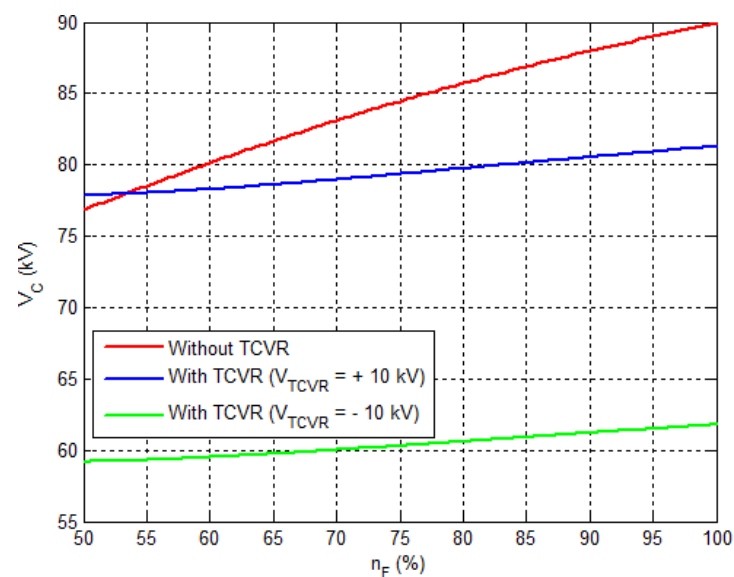

(c)

Figure 8. Impact of $n_{F}$ on the transmission line phase voltages

\section{CONCLUSION}

In this research work, short-circuit analysis of a phase to earth fault is derived using symmetrical components method for a practical high voltage transmission line in the $220 \mathrm{kV}$ Algerian power network. The line is equipped with one of the recent FACTS devices; namely TCVR which works to regulate the voltage of the line. While using TCVR, the effect of fault location on short-circuit calculation parameters, in case of positive and negative TCVR controlled voltages, is investigated while maintaining a fixed fault resistance. The theoretical analysis using symmetrical components and simulations of the proposed model, before and after using TCVR, showed excellent agreement.

From this paper, it is confirmed that the use of TCVR leads to a significant reduction in the fault current. In the meanwhile, it is clear that increasing the value of the fault location leads to a reduction in the current symmetrical components, in the absence and presence of TCVR, with a noticeable declination in the magnitude of the fault current.

Further research studies while using TCVR are currently under investigation for ongoing publications. These include various short-circuit cases such as three phase fault and phase to phase fault, as well as studying the effect of fault resistance on short-circuit calculations.

\section{REFERENCES}

[1]. J. Schlabbach, "Short-Circuit Currents", second edition, published by The Institution of Engineering and Technology (IET), London, UK, June 2008.

[2]. A. Berizzi, S. Massucco, A. Silvestri, and D. Zaninelli, "Short-Circuit Current Calculation: A Comparison Between Methods of IEC and ANSI Standards using Dynamic Simulation as Reference", IEEE Transactions on Industry Applications, Vol. 30, No. 4, pp. 1099-1106, 1994. 
[3]. L. Hewitson, M. Brown, and B. Ramesh, "Practical Power Systems Protection", Published by Elsevier, Oxford, United Kingdom, 2004.

[4]. M. M. Eissa, "Ground Distance Relay Compensation based on Fault Resistance Calculation", IEEE Transactions on Power Delivery, Vol. 21, No. 4, pp. 1830-1835, 2006.

[5]. G. Yanfeng, and A. Guzman, "Advanced Fault Location Solution for Distribution Systems using IED Information and the Detailed Feeder Model", IEEE Asia-Pacific Power and Energy Engineering Conference (APPEEC), Shanghai - China, 27-29 March, 2012.

[6]. P. Dutta, and M. Kezunovic, "Fault Resistance Sensitivity of Sparse Measurement based Transmission Line Fault Location", IEEE North American Power Symposium (NAPS), Boston, USA, 4-6 August, 2011.

[7]. H. Livani, and C.Y. Evrenosoglu, "A Machine Learning and Wavelet-Based Fault Location Method for Hybrid Transmission Lines", IEEE Transactions on Smart Grid, Vol. 5, No. 1, pp. 51-59, 2014.

[8]. M. Rhulani, B. Adam, and Z. Rastko, "Impact of High Resistance Faults on Impedance Protection Performance", $18^{\text {th }}$ International Conference and Exhibition on Electricity Distribution (CIRED), Turin, Italy, 6-9 June, 2005.

[9]. V. H. Makwana, and B. Bhalja, "New Adaptive Digital Distance Relaying Scheme for Double Infeed Parallel Transmission Line During Inter-Circuit Faults", IET Generation, Transmission \& Distribution, Vol. 5, No. 6, pp. 667-673, 2011.

[10]. P. H. Shah, and B. R. Bhalja, "New Adaptive Digital Relaying Scheme to Tackle Recloser-Fuse Miscoordination Guring Distributed Generation Interconnections", IET Generation, Transmission \& Distribution, Vol. 8, No. 4, pp. 682-688, 2014.

[11]. K. Seethalekshmi, S. N. Singh, and S. C. Srivastava, "Synchrophasor Assisted Adaptive Reach Setting of Distance Relays in Presence of UPFC", IEEE Systems Journal, Vol. 5, No. 3, pp. 396-405, 2011.

[12]. J. Suonan, X. Deng, and G. Song, "A Novel Busbar Protection Based on Fault Component Integrated Impedance", IEEE Asia-Pacific Power and Energy Engineering Conference (APPEEC), Chengdu, China, 28-31 March, 2010.

[13]. F. Coffele, C. Booth, A. Dyśko, and G. Burt, "Quantitative Analysis of Network Protection Blinding for Systems Incorporating Distributed Generation", IET Generation, Transmission \& Distribution, Vol. 6, No. 12, pp. 1218$1224,2012$.

[14]. Z. Bi-Chang, and Z. Hong, "Fault Location of Distribution Network Containing Distributed Generations", TELKOMNIKA Indonesian Journal of Electrical Engineering, Vol. 12, No. 8, pp. 5910-5917, 2014.

[15]. M. Zellagui, and A. Chaghi, "Impact of TCSC on Measured Impedance by MHO Distance Relay on $400 \mathrm{kV}$ Algerian Transmission Line in Presence of Phase to Earth Fault", Journal of Electrical Systems (JES), Vol. 8, No. 3, pp. 273-291, 2012

[16]. Y. Liu, "Study on Reactance Relays for Single Phase to Earth Fault on EHV Transmission Lines", TELKOMNIKA Indonesian Journal of Electrical Engineering, Vol. 11, No. 7, pp. 3855-3862, 2013.

[17]. M. Zellagui, and A. Chaghi, "Impact of Apparent Reactance Injected by TCSR on Distance Relay in Presence Phase to Earth Fault", Advances in Electrical and Electronic Engineering (AEEE), Vol. 11, No. 3, pp. 156-168, 2013.

[18]. S. Gerbex, R. Cherkaoui, and A. J. Germond, "Optimal Location of Multi-Type FACTS Devices in a Power System by Means of Genetic Algorithms", IEEE Transactions on Power Systems, Vol. 16, No. 3, pp. 537-544, 2001.

[19]. E. Ghahremani, and I. Kamwa, "Maximizing Transmission Capacity Through a Minimum Set of Distributed MultiType FACTS", IEEE Power and Energy Society General Meeting, San Diego, USA, 22-26 July, 2012.

[20]. C. L. Fortescue, "Method of Symmetrical Coordinates Applied to the Solution of Polyphase Networks", IEEE Transactions of AIEE, Vol. 37, pp. 1027-1140, 1918.

[21]. J. Schlabbach, "Short-Circuit Currents", second edition, published by Institution of Engineering and Technology (IET), London, United Kingdom, 2008.

[22]. M. Zellagui, H. Hassan, and A. Chaghi, "Short-Circuit Calculations for a Transmission Line in the Algerian Power Network Compensated by Thyristor Controlled Voltage Regulator", Journal of Electrical and Electronics Engineering (JEEE), Vol. 7, No. 2, pp. 43-48, 2014.

[23]. S. Jamali, and H. Shateri, "Impedance based Fault Location Method for Single Phase to Earth Faults in Transmission Systems", $10^{\text {th }}$ IET International Conference on Developments in Power System Protection (DPSP), Manchester, UK, 29 March - 1 April, 2010.

[24]. J. L. Blackburn, and A. F. Sleva, "Symmetrical Components for Power Systems Engineering", second edition, published by CRC press, London, United Kingdom, 2011.

[25]. Sonelgaz Group, "Topology of Eastern Transmission Networks High Voltage 220 kV", Algerian Company of Electrical Transmission, GRTE, Algiers, Algeria, December 2013. 


\section{BIOGRAPHIES OF AUTHORS}

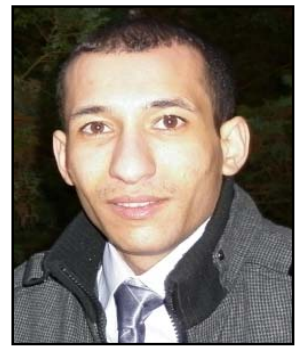

Mohamed Zellagui. He received his engineering degree (Honors with first class) and M.Sc. degree in Electrical Engineering (Power System) from the Department of Electrical Engineering, University of Constantine, Algeria in 2007 and 2010 respectively. He received Doctor Degree in Power Systems from the Department of Electrical Engineering, University of Batna, Algeria in 2014. He is a member of LSP-IE research laboratory at Batna University, Algeria. In 2012, Dr. Zellagui obtained the national award for the best PhD student in science and technology. He has membership at International Association of Engineers (IAENG), Institute of Electrical and Electronics Engineers (IEEE)-USA, Power and Energy Society (PES), and Smart Grid Community (SGC). He is a Senior Member of Universal Association of Computer and Electronics Engineers (UACEE), International Scientific Academy of Engineering and Technology (ISAET) and International Association of Computer Science and Information Technology (IACSIT). He is on the Editorial Board of the Journal of Electrical and Electronics Engineering (JEEE) and International Journal of Electronic and Electrical Engineering (IJEEE). His research interests include power systems protection, short-circuit calculations, distance relays, renewable energy, and FACTS devices.

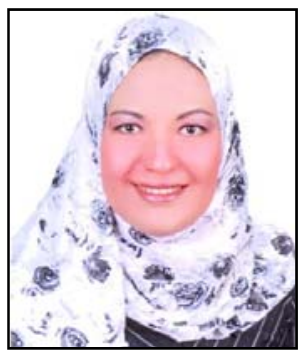

Heba Ahmed Hassan. She received her B.Sc. and M.Sc. with Distinction First Honors degree from Electrical Power and Machines Department, Faculty of Engineering, Cairo University, Egypt, in 1995 and 1999, respectively. She obtained her Ph.D. degree in Electrical Engineering from the University of Ulster, U.K, in 2004 when she was selected to present her Ph.D. work at the House of Commons, Parliament House, Westminster, London, UK. She joined Dhofar University, Salalah, Oman in 2008 where she was promoted to several senior leadership positions. She was the Acting Dean and Assistant Dean of College of Engineering, Dhofar University. Currently, she is an academic member of the Quality Assurance Unit of Dhofar University. She is also the university representative at Oman Quality Network (OQN) and Oman Academic Accreditation Authority (OAAA). She has been appointed to OAAA's Register of External Reviewers in June 2014.

Dr. Hassan is a full-time faculty (2005-present) in Electrical Power and Machines Department, Cairo University, currently on leave. She was an Academic Visitor at the Imperial College, London, UK (1998), a Teaching and Research Assistant at the University of Ulster, UK (20012005), and a part-time faculty at many respectable private engineering universities in Egypt (2005-2008). During that period, she worked as a quality auditor for the Quality Assurance and Accreditation Project (QAAP) and a consultant for several Egyptian MoHE development projects which were all financed by the International Bank for Reconstruction and Development (IBRD).

She co-supervised 2 M.Sc. Students, Faculty of Engineering, Cairo University (2005-2012). Dr. Hassan was selected by reputable universities in India to act as an External Ph.D. Examiner and as a Keynote Speaker for several international conferences. She was appointed by the Omani MoHE as a Reviewer of newly submitted academic programs. Dr. Hassan is a Senior IEEE member (SMIEEE), an IET Member (MIET), an Associate Fellow of the Higher Education Academy-UK (AFHEA), and a Certified Associate Academic Trainer by the International Board of Certified Trainers (IBCT) who conducted many training programs for academic staff on effective teaching and assessment. She is the Chief Editor of two international referred journals in the field. She is also serving as an Associate Editor, an Editorial Board Member, and a Reviewer for many international journals and conferences in power engineering. She has always been a member of IEEE societies such as Power and Energy Society (PES), Control Systems Society (CSS), and Women in Engineering (WIE). Dr. Hassan research interests include electrical power systems stability and control, FACTS modeling, optimal and robust adaptive control, and quality of higher education related studies.

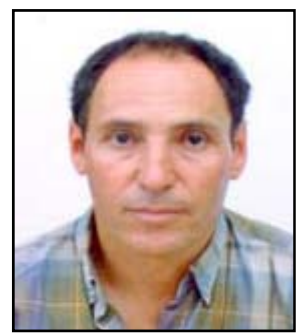

Abdelaziz Chaghi. He received his engineering degree from the University of Oran, Algeria in 1980, and M.Sc. from Manchester University, United Kingdom in 1984. He received Doctor Degree in Power Systems from University of Batna, Algeria in 2004. Professor Chaghi is responsible for the research team in charge of "Power quality in distribution power systems" at LSP-IE research laboratory, University of Batna. His research interests include power systems optimization, power electronics, power quality, renewable energy, harmonic, and FACTS devices modeling and control. 